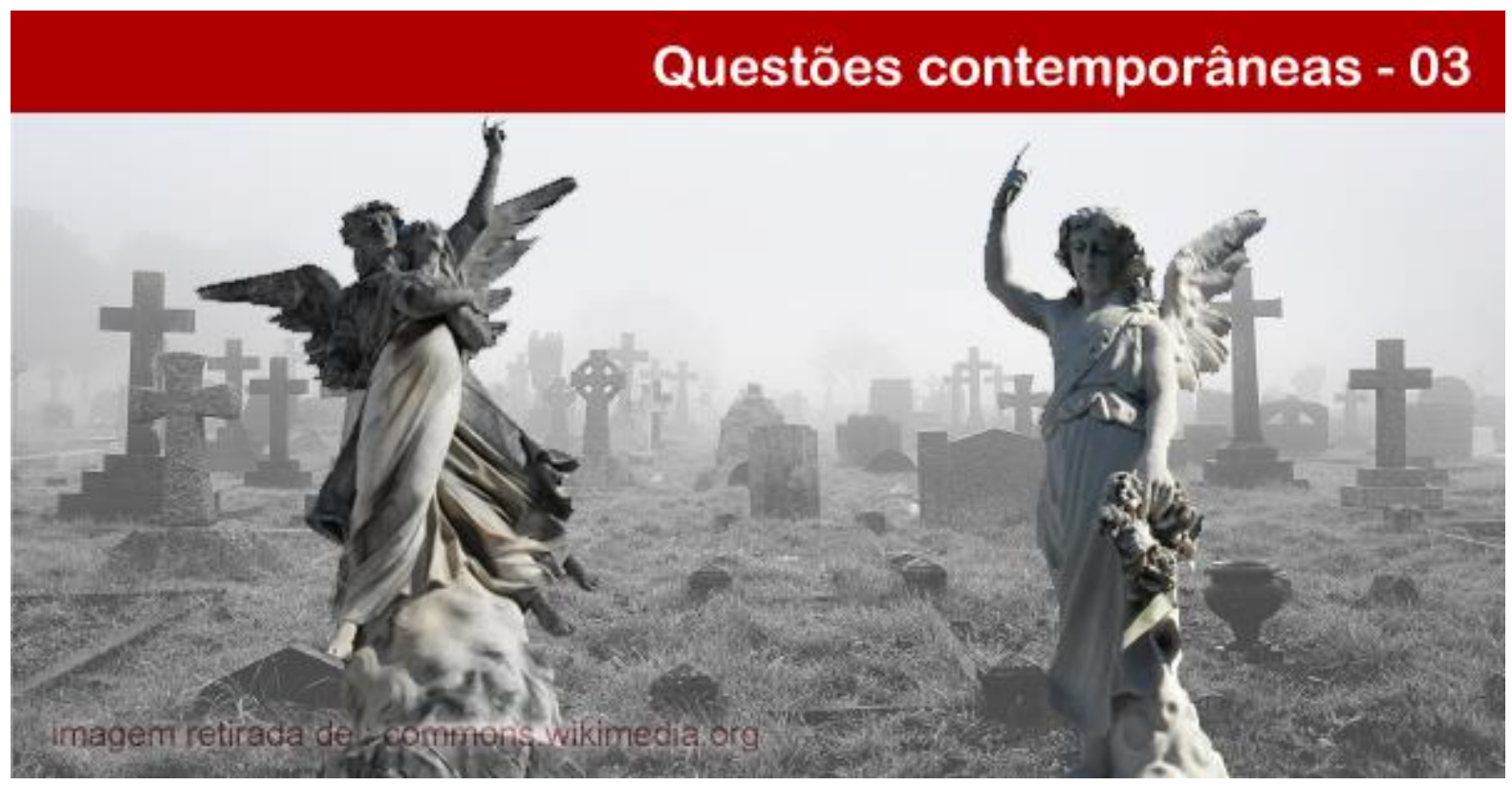

\title{
AS BIOTECNOLOGIAS E A MORTE: REFLEXÕES SOBRE O ENFRENTAMENTO DA MORTE ATRAVÉS DA TRANSCENDÊNCIA ARTIFICIAL
}

\author{
Veronica Santana Queiroz \\ Graduação em Psicologia pela Universidade do Estado do Rio de Janeiro. Especialização em Saúde Pública \\ pela ENSP / FIOCRUZ. Mestre em Psicologia Social pela Universidade do Estado do Rio de Janeiro. E-mail: \\ veronicasqueiroz@gmail.com.
}

Resumo: A hipermodernidade trouxe mudanças nos modos de pensar, agir, viver e morrer. As biotecnologias têm nos mostrado possíveis cenários que muitas vezes parecem apontar para algo da ordem do fantástico, e no que concerne a este artigo, elas acenam para a possibilidade de superar condições tipicamente humanas. Na hipermodernidade, a morte se tornou um "problema" a ser "resolvido" e com essa interpretação, intervenções pautadas na ciência se tornaram necessárias, como os medicamentos, as inovações tecnológicas e mudanças nos modos de enfrentamento da morte, acarretando na hipervalorização da vida e no afastamento da morte. Este artigo trata-se de uma reflexão a partir de uma matéria publicada recentemente sobre o uso de droga alucinógena para o enfrentamento da condição de doença terminal a fim de levar o usuário a não ter medo da morte por meio da "experiência mística" gerada como efeito da substância.

Palavras-chave: Morte. Enfrentamento. Medicalização. Experiência mística.

\section{THE BIOTECHNOLOGIES AND DEATH: REFLECTIONS ABOUT COPING DEATH THROUGHT ARTIFICIAL TRANSCENDENCE}

\begin{abstract}
The hipermodernity brought changes in the ways of thinking, acting, living and dying. The biotechnologies have shown us possible scenarios which often in many cases seem to be unreal and, as regards this article, they suggest the possibility of overcoming the human natural conditions. In hypermodernity, death became a "problem" to be "solved", and this idea demands science interventions: medicines, technological innovations, changes in methods of facing mortality, overvaluation of life and a distance from death. This article is a reflection based on a recently published article about the use of hallucinogenic drugs for facing the terminal disease condition in order to bring the user to have no fear of death through "mystical experience" generated as an effect of the substance.
\end{abstract}

Keywords: Death. Coping. Medicalization. Mystical experience.

\section{POLÊM!CA $\mid$ LABORE (3:}

Polêmica - Revista Eletrônica da Uerj - Rua São Francisco Xavier, 524, $1^{\circ}$ andar bloco D, sl.1001 • Tels.: +55 21 2334-4088 / 4087 • http://www.e-publicacoes.uerj.br/index.php/polemica/index http://www.labore.uerj.br • laboreuerj@yahoo.com.br 
Este artigo trata-se de uma reflexão sobre a hipermodernidade e seus modos de enfrentamentos da morte, motivada a partir de uma matéria publicada na revista Piauí, edição 105 (junho de 2015), intitulada Doce Remédio, onde uma pesquisa pretende, com o uso de drogas alucinógenas, proporcionar experiências místicas em pessoas em estado terminal provocado por câncer acreditando que a "espiritualidade" pode ser terapêutica nesses casos, como por exemplo, o sujeito acometido da doença superar o medo da morte.

A metodologia se pautou em leituras sobre autores que pensam sobre a contemporaneidade e a morte como um fenômeno sócio-cultural e não apenas um fenômeno biológico. Trata-se de refletir sobre como a intervenção das biotecnologias tem impulsionado não somente as transformações tecnológicas como também influenciado modos de viver e de morrer.

\section{Cenário contemporâneo: líquido e excesso}

Líquido e excesso. São palavras que caracterizam a contemporaneidade segundo Bauman (2001) e Lipovetsky (2004), o primeiro é sociólogo polonês e o segundo, filósofo francês.

Bauman retira o termo "líquido" da própria Física, para caracterizar um estado fluido, volátil e inconstante. Assim, Bauman (2001) dirá que esse é um traço da atualidade, onde a vida e as relações se tornaram líquidas e rapidamente mutáveis. As tradições e instituições (como a Igreja, o Estado, partidos políticos, a família) que regulavam a vida social e individual, que outrora eram sólidos e estáveis e suas ligas eram firmes, se dissolveram e hoje é "cada um por si", ou seja, recaiu a responsabilidade do fracasso ou sucesso ao próprio indivíduo. Essas mudanças de estados (do sólido para o líquido) se deram sem que fosse necessária nenhuma revolução ou ditadura, mas foi uma transição imposta pelo capitalismo e pela globalização, vigentes até hoje, e com isso a substituição de antigas concepções por outras que se supõem melhores para as pessoas, para o mundo e para o próprio sistema capitalista. Segundo Bauman (2001) "o derretimento dos sólidos” surgiu "para substituir o conjunto herdado de sólidos deficientes e defeituosos por outro conjunto, aperfeiçoado e preferivelmente perfeito [...]" (p. 9).

\section{POLÊM!CA $\mid$ LABORE}


Lipovetsky (2004) cunha o termo "hipermodernidade" "numa tentativa de interpretar a época atual, descrevendo-a marcada principalmente pela lógica do excesso, do "hiper". Hipervelocidade, hipermercado, hiperatividade. Este autor aponta três eixos que sustentam tal sociedade: o mercado, o indivíduo e a eficiência técnica, explicados a seguir.

A sociedade liberal, capitalista e democrática (em termos) dita a livre circulação de mercadorias, a não interferência do Estado, e, portanto, a não regulação da dinâmica econômica e o ideal de que todos podem adquirir os bens e os serviços que desejarem ${ }^{2}$. O que antes se restringia à esfera econômica e administrativa invade e passa a mediar as relações íntimas do cidadão comum (LIPOVETSKY, 2004; CHARLES, 2004). Noções como "liberalismo", "flexibilidade" e "custo-benefício" são hoje palavras que compõem as relações humanas, seja no trabalho ou nas relações amorosas.

No que tange aos indivíduos, uma das características saltitantes aos olhos é o hipernarcisismo. O homem hipermoderno quer gozar ininterruptamente, "agora, a motivação é outra: a satisfação pessoal, estar bem consigo mesmo, gozar (SILVA apud LIPOVETSKY, 2007, p. xviii).

A eficiência técnica é a predominância da "racionalidade instrumental", que é a crença absoluta de que o progresso científico, tecnológico e suas metodologias baseadas no pragmatismo e no utilitarismo são o caminho pelo qual o homem será verdadeiramente livre, mas na verdade esse "progresso" está muitas vezes submetido aos ditames do mercado. Quer dizer, o "progresso" não atenderá necessariamente as demandas das populações, mas as do mercado, isto é, o lucro prevalece em detrimento de outras necessidades. Tal pensamento se exprime quando o Estado incentiva o "crescimento da economia" em termos de rentabilidade aos empresários e indústrias, mas não na melhoria da qualidade de vida dos cidadãos, por exemplo.

Essas características da presente época se somam à lógica do "mais que bem" (BEZERRA, 2010) e se deve ao fato de as biotecnologias prometerem ao homem que ele deve superar o estado de bem-estar para estar além de suas capacidades, deve se encontrar numa condição de controlar e administrar os males e os sofrimentos da vida. O uso de drogas que potencializam as capacidades humanas surge na tentativa de otimizar o desempenho do

\footnotetext{
${ }^{1}$ Lipovetsky (2004) adota o conceito de "hipermodernidade" como uma continuação da modernidade superlativada e com características próprias que a difere essencialmente da modernidade. Adotarei o conceito de hipermodernidade por considerar que melhor retrata a época atual.

${ }^{2}$ Esse ideal só é efetivado desde que os sujeitos considerados como consumidores tenham o poder de consumir, caso contrário, esse mesmo sujeito-consumidor fica à margem da sociedade de consumo.
}

\section{POLÊM!CA | LABORË}

Polêmica - Revista Eletrônica da Uerj - Rua São Francisco Xavier, 524, $1^{\circ}$ andar bloco D, sl.1001 • Tels.: +55 21 2334-4088 / 4087 • http://www.e-publicacoes.uerj.br/index.php/polemica/index http://www.labore.uerj.br • laboreuerj@yahoo.com.br 
indivíduo e nisso subjaz uma tentativa de mascarar os aspectos tipicamente humanos. Drogas que agem no organismo humano como estimulantes sexuais, estimulantes da vigília (bloqueiam o sono), estimulantes da atividade (bloqueiam a fadiga), estimulantes de uma vida sobre-humana, caracterizam uma tendência de medicalização da vida. Há a crença, portanto, de que "pela estimulação farmacológica tudo se tornaria, então, possível para o indivíduo, não existindo mais para ele qualquer obstáculo" (BIRMAN, 2010, p. 43), estabelecendo-se o imperativo da hiperperformance para os indivíduos.

\section{Utopia da imortalidade e a virtualidade}

Outra tendência notável é a centralidade do cérebro humano como o cerne da existência. Os especialistas na área de inteligência artificial e neurociências acreditam que o que define a vida é a informação e não mais a subjetividade ou o psiquismo que outrora ocupava o centro da atenção de muitos pensadores como uma "substância" imaterial, muitas vezes divinal e misteriosa; hoje o grande mistério da vida parece estar codificado nas sinapses, nos circuitos cerebrais, em suma, no cérebro. E sendo informação, ela pode ser acessada, digitalizada, reprogramada e virtualizada, portanto, a subjetividade parece estar sendo cada vez mais objetificada em processos informatizados, sejam eles neuroquímicos, cerebrais ou nos códigos genéticos.

Sibilia (2011) nos mostra claramente esse processo: "Poderiam ser superadas, assim, certas fraquezas desse corpo teimosamente material em sua rigidez analógica, que por isso se apresenta como deficitário ou obsoleto na atualidade, precisando ser 'melhorado' com recursos técnicos" (p. 12, grifo da autora). Sibilia $(2002,2011)$ traz algumas reflexões, as quais se seguem: a ideia de extravasamento dos limites humanos, o corpo humano como aquilo que se torna facilmente obsoleto e ultrapassado e a noção de aperfeiçoamento. A partir dessas premissas vão surgir novos paradigmas como o "culto ao cérebro", o projeto futurista do homem como um avatar, a possibilidade de fazer upgrade ou download do cérebro, congelar o corpo morto para "ressuscitá-lo" no futuro e até transformar a pessoa falecida em um programa de celular que reproduz sua voz e expressões típicas e posteriormente transformá-la num andróide com dimensões e expressões exatas ${ }^{4}$. Tais ideias futuristas

\footnotetext{
${ }^{3}$ Entendo avatar como uma representação virtual do usuário, como um personagem que o usuário cria para ser identificado nas redes sociais ou jogos.

${ }^{4}$ Episódio Be right back (Volto já) da série inglesa Black Mirror. Otto Bathurst, Euros Lyn, Brian Welsh, Owen Harris, Bryn Higgins, Carl Tibetts. Inglaterra, 2011.
}

\section{POLÊM!CA $\mid$ LABORE}


sinalizam um cenário fantástico de ficção científica com algumas possibilidades de reflexão, das quais fica evidente uma tentativa de imortalizar o indivíduo, isto é, uma tentativa de transcender a limitação da vida humana.

Observam-se então dois sinais do tempo presente: primeiro, a valorização do corpo saudável e segundo, a concepção de que o corpo é falho porque se degenera e, portanto, a busca de um lugar virtual, onde a mente $e^{5}$ poderia habitar "livremente". São possíveis algumas interpretações dessas tendências: a primeira, de que o corpo saudável seria um sinal de jovialidade e de vida; e a segunda, de que o abandono do corpo físico e mortal para um lugar virtual demonstraria um distanciamento da mortalidade, já que os seres habitariam um espaço onde a "vida" poderia se tornar eterna, uma vida online. A virtualidade promete a imortalidade (QUEIROZ, 2013, p. 109).

Uma figura exemplar deste raciocínio é o Robocop ${ }^{6}$, personagem lançado na década de 1980. O filme conta a história de um policial que é morto e seu cérebro é transplantado para um robô que combate o crime. $\mathrm{O}$ interessante é que as lembranças do policial reverberam no ciborgue, fazendo dele uma máquina com sentimentos de humano. Segundo Sibilia (2002), o aprimoramento técnico estaria anunciando uma era "pós-orgânica", onde o homem e a tecnologia estariam se fundindo (ou confundindo). Segundo Haraway, Kunzru e Tadeu (2009), o ciborgue seria uma relação tão íntima entre homem e a tecnologia que não seria mais "possível dizer onde nós acabamos e onde as máquinas começam" (p. 22). E complementaria dizendo que essa assimilação faz com que o homem hipermoderno acredite ser impossível viver sem a tecnologia que hoje se dispõe. É importante considerar, contudo, que, apesar do intenso investimento em pesquisas na área tecnológica, à medida que se desvenda a intimidade do organismo vivo, esse avanço corresponde na mesma proporção ao aumento da complexidade, então, ainda que o homem anseie inaugurar uma nova era, ainda terá que pacientemente se deparar com mistérios cada vez mais complexos.

$\mathrm{Na}$ esteira desse incentivo nas áreas biotecnológicas há um movimento de declínio no número de adeptos religiosos no mundo e no Brasil ${ }^{7}$, talvez por causa da forte crença na razão

\footnotetext{
${ }^{5}$ A mente aqui é entendida como o sistema cerebral.

${ }^{6}$ Robocop, O policial do futuro (RoboCop). Paul Verhoeven. EUA, 1987.

7 "Religião cai em todo mundo e despenca na Irlanda". Disponível em: <http://oglobo.globo.com/mundo/religiao-cai-em-todo-mundo-despenca-na-irlanda-5737597>. Acesso em: agosto de 2012.

“Censo 2010: número de católicos cai e aumenta o de evangélicos, espíritas e sem religião". Disponível em: $<$ http://www.censo2010.ibge.gov.br/noticias-censo?view=noticia\&id=1\&idnoticia=2170\&t=censo-2010numero-catolicos-cai-aumenta-evangelicos-espiritas-sem-religiao>. Acesso em: maio de 2016.
}

\section{POLÊM!CA | LABORE.}

Polêmica - Revista Eletrônica da Uerj - Rua São Francisco Xavier, 524, $1^{\circ}$ andar bloco D, sl.1001 • Tels.: +55 21 2334-4088 / 4087 • http://www.e-publicacoes.uerj.br/index.php/polemica/index http://www.labore.uerj.br • laboreuerj@yahoo.com.br 
instrumental. Segundo Lipovetsky $(2001,2007)$, um dos maiores fatores de decepção atual é o enfraquecimento das religiões. Se por um lado cresce o número de seitas e de um sentimento fundamentalista religioso, paradoxalmente, por outro, aumenta a descrença, e afirma ainda que na falta desse tipo de referência as pessoas sentem-se frustradas e desamparadas. A fé religiosa se tornou alvo de depreciação e é atacada muitas vezes por ser considerada "irracional" mediante a "racionalidade" científica.

\section{Terminalidade humana e a transcendência artificial}

Nesse contexto onde as biotecnologias exercem poder e controle sobre "a verdade", nos parece que a "fé" e as esperanças têm sido depositadas nas capacidades que essas ciências prometem alcançar e não mais no lugar que outrora era ocupado pelas religiões.

A transcendência e a metafísica, dimensões obscuras e misteriosas, parecem pertencer às biotecnologias que promovem "milagres" e, quem opera esse "poder" não é mais o místico ou o sacerdote, mas sim o técnico representado muitas vezes pelo médico ou o cientista (MENEZES, 2013). Segundo Menezes (2013), no processo de morte, houve algumas mudanças: o religioso perde a sua autoridade e o médico emerge como a figura de referência para este momento e a ênfase na transcendência perde a força, a ênfase agora é na fisicalidade, isto é, no corpo e nos seus processos bioquímicos.

No entanto, o saber científico almeja criar a experiência religiosa por seus próprios meios, a exemplo disso, chama atenção uma pesquisa para "reavaliar o potencial terapêutico de drogas psicodélicas" ${ }^{\prime}$. Para esta pesquisa, ainda em caráter experimental, usa-se uma droga chamada psilocibina, que é o princípio ativo, em pacientes terminais de câncer cuja proposta dos pesquisadores é levá-los a terem experiências transcendentais e místicas induzidas pela droga, a fim de ter um efeito terapêutico sobre a condição de terminalidade, como por exemplo, tratar o medo da morte, além de outras expectativas como o de "aperfeiçoamento de gente saudável". A pesquisa realizada nos Estados Unidos, pela Universidade de Nova York (NYU), admite voluntários após uma triagem minuciosa e um acompanhamento rigoroso.

8 Matéria intitulada Doce remédio, da revista Piauí, edição de junho de 2015 . Disponível em: <http://revistapiaui.estadao.com.br/edicao-105/anais-da-medicina/doce-remedio>. Acesso em 08 julho 2015.

\section{POLÊM!CA $\mid$ LABORE}

Polêmica - Revista Eletrônica da Uerj - Rua São Francisco Xavier, 524, $1^{\circ}$ andar bloco D, sl.1001 • Tels.: +55 21 2334-4088 / 4087 • http://www.e-publicacoes.uerj.br/index.php/polemica/index http://www.labore.uerj.br • laboreuerj@yahoo.com.br 
Este tipo de estudo nos faz refletir sobre a tentativa das biotecnologias em conduzir o homem a um estado de "espiritualidade", ou seja, os pesquisadores acreditam que por meio da interferência de drogas e de alterações neuroquímicas é possível fazer o sujeito viver "uma experiência de conversão" (expressão utilizada na matéria), confirmada pela passagem na matéria que diz que os estudos com a psilocibina pretendem "estudar a neurobiologia da experiência mística".

Pode-se pensar em alguns aspectos que esse estudo suscita. Primeiro, a necessidade de intervenção externa para a "experiência mística", isto é, o sujeito não construiria a sua experiência religiosa idiossincrática, não precisaria se submeter a uma disciplina religiosa, não dedicaria seu tempo para estudar uma determinada religião e viver um processo constante de reflexão, bastaria apenas tomar a droga.

Segundo, as alucinações decorrentes do uso da droga teriam um efeito terapêutico de acordo com os pesquisadores, mas será que o sujeito, sem o uso da droga, poderia atingir esse mesmo grau atingido com o uso da droga ou será que seria dependente dela para se sentir feliz ou capaz de enfrentar a morte sem ansiedade ou depressão? Não seriam a ansiedade e a depressão mecanismos esperados e até normais diante da morte? Qual seria o nível de autonomia desses sujeitos para viverem essa experiência religiosa?

Esses dois questionamentos demonstram que tal estudo acompanha os tempos hipermodernos e suas tendências: o indivíduo contemporâneo tem a urgência de calar o sofrimento e, em geral, recorre às medicações para apaziguá-lo, pois o efeito é rápido e segue as suas conveniências. Além disso, não são conhecidas as consequências do uso da psilocibina a longo prazo, e, se continuar a ser testada em pacientes terminais, ficará difícil saber, pois os pacientes que se submeterão ao experimento morrerão. Parece que a transcendência ou a experiência mística como terapêutica no processo de fim de vida está sendo medicalizada.

Outra reflexão sobre essas perguntas é: não seria a experiência religiosa construída pela reflexão contínua do sujeito com base em suas experiências de vida e na interação com o outro conjugada com aquela dimensão insondável que se conecta com a espiritualidade? Seria possível criar a "fé" em laboratório?

No entanto, existe um movimento que defende a "naturalidade" da morte que, por um lado, apóia o uso de drogas psicoativas no tratamento no fim da vida, e por outro, desestimula as intervenções tecnológicas, como o uso dos fármacos, e incentiva o retorno àquilo que seria natural durante o processo de morte. Em 1991 foi fundada na Inglaterra uma instituição

\section{POLÊM!CA $\mid$ LABORE}

Polêmica - Revista Eletrônica da Uerj - Rua São Francisco Xavier, 524, $1^{\circ}$ andar bloco D, sl.1001 • Tels.: +55 21 2334-4088 / 4087 • http://www.e-publicacoes.uerj.br/index.php/polemica/index http://www.labore.uerj.br • laboreuerj@yahoo.com.br 
educacional chamada Natural Death Center para divulgar a concepção de "morte natural" em alusão ao movimento do "parto natural". Propõe um novo modelo de cuidado do processo de morrer que dê mais visibilidade à morte, que envolva mudanças nas políticas públicas e na formação dos profissionais de saúde, como também estendendo ações para a sociedade.

A concepção de "morte natural" sustenta práticas que deleguem mais autonomia aos doentes, bem como um retorno ao ambiente e a terapêuticas mais naturais possíveis, como por exemplo, ter acesso à natureza, aos animais de estimação e a tratamentos como massagens corporais e exercícios de relaxamento e respiratórios.

As ações voltadas para a redução da ansiedade diante da morte incluem também o uso de drogas psicoativas em que o objetivo seria alcançar uma percepção mais apurada do processo de morte (MENEZES, 2003). Estamos diante de um cenário complexo onde diversos modelos de assistência ao processo de morte disputam concepções heterogêneas, e, portanto, o debate está em pleno curso. Nos exemplos apresentados, os modos de enfrentamentos diante da morte por doença terminal divergem, um centraliza no uso de drogas alucinógenas (no caso, a psilocibina); o outro, no caso da "morte natural", há o incentivo do uso de drogas psicoativas em conjunto com práticas "naturais", todavia há a recusa de intervenções por meio dos fármacos. Contudo, é necessário reconhecer a importância das medicações industrializadas no tratamento das doenças terminais, sobretudo no controle da dor. Deve-se ter a devida atenção para não radicalizar, favorecendo apenas uma forma de terapêutica em detrimento de outras.

Penso que a morte e aquilo que ela suscita deveriam ter lugares para serem expressos abertamente, talvez assim, com espaço para a fala e para a escuta, os sujeitos a enfrentassem com menos ansiedade ou depressão, talvez ao nos aproximarmos da tão temida morte, ela se transformasse em um fenômeno mais natural e diminuísse o peso desse evento tão marcante.

Parece que para haver "espiritualidade" ela precisa ser racionalizada e validada pela ciência dentro dos seus moldes: necessita de pesquisa, de metodologias científicas, experimentos e culmina quase sempre numa medicação.

Seria uma tendência em reduzir o "eu" ao cérebro e às suas atividades neuronais? Não indicaria uma tentativa de objetificar o ser humano e sua subjetividade? Essa matéria da revista Piauí intitulada "Doce Remédio" parece demonstrar o quanto o ser humano e suas experiências têm sido limitados ao sistema neurofisiológico, desconsiderando suas experiências sociais, subjetivas e sua singularidade. Aqui fica notável uma inversão de lógica

\section{POLÊM!CA $\mid$ LABORE}

Polêmica - Revista Eletrônica da Uerj - Rua São Francisco Xavier, 524, $1^{\circ}$ andar bloco D, sl.1001 • Tels.: +55 21 2334-4088 / 4087 • http://www.e-publicacoes.uerj.br/index.php/polemica/index http://www.labore.uerj.br • laboreuerj@yahoo.com.br 
cultivada ao longo do tempo e, não diferente, na hipermodernidade: a subjetividade está sendo transformada em objeto manipulável, previsível e concreto.

Segundo Bezerra (2010), alguns aspectos incidem nesse cenário hipermoderno de medicalização, como: a expansão dos diagnósticos de transtornos mentais que são absorvidos pela população; a diferença entre a normalidade e a patologia cada vez mais tênues e a dissolução da fronteira entre tratamento e aperfeiçoamento.

A partir dessas três observações podem-se tecer algumas considerações. A expansão dos diagnósticos dos transtornos mentais se materializa na última versão do DSM- $5^{9}$. A noção de prevenção e de intervenção precoce para evitar os transtornos mentais que possam ocorrer no futuro é preocupante e uma delas é a medicalização da tristeza e do luto como formas de prevenir o transtorno de Depressão Maior. A proposta do DSM-5, com relação ao diagnóstico de Depressão Maior, aponta para um estreitamento entre o que poderia ser considerado experiências comuns à condição humana diante de perdas e uma patologia. Características como duas semanas de humor deprimido, desinteresse em atividades cotidianas, insônia, perda de apetite e problemas de concentração bastariam para validar um diagnóstico de transtorno mental (BEZERRA, 2010). Assim, podemos observar que o limite entre o que é saudável e o que é não saudável está se misturando, o que significa dizer que muito do que é classificado hoje como "desvio" ou "deficiência" são inerentes à existência humana. A ideia de aperfeiçoamento possibilitado pelas biotecnologias expressa o desejo de superar, de superlativar aquilo que já é, o que Sibilia (2002) chama de "fáustico", isto é, o esforço de ultrapassar as limitações humanas.

Devemos considerar que a relação do homem com a morte se modifica ao longo da história segundo a cultura, a influência da religião dominante e os aspectos sociais por exemplo. O historiador francês Phillipe Ariès (1977) fez um grande estudo das atitudes do homem diante da morte desde a Idade Média até o século XX na Europa e nos mostra diferentes modos de enfretamento da morte ao longo da história ocidental que vem mudando até os dias de hoje.

Ariès (1977) detalha quatro momentos sobre as atitudes diante da morte, e será destacado no presente artigo o que o autor (ARIÈS, 1977) caracteriza como a "morte domada", optei por abordar esse momento histórico por considerar que é a concepção de

9 DSM: Diagnostic and Estatistical Manual of Mental Disorders, traduzido como Manual Diagnóstico e Estatístico de Transtornos Mentais.

\section{POLÊM!CA $\mid$ LABORE}

Polêmica - Revista Eletrônica da Uerj - Rua São Francisco Xavier, 524, $1^{\circ}$ andar bloco D, sl.1001 • Tels.: +55 21 2334-4088/4087 • http://www.e-publicacoes.uerj.br/index.php/polemica/index http://www.labore.uerj.br • laboreuerj@yahoo.com.br 
morte que mais se difere da hipermoderna. A fase chamada de "morte domada" diz respeito ao período anterior ao século XII, durante a época medieval, onde a morte era algo simples e entendida como uma destinação coletiva, havia uma resignação diante da morte. Tinha-se uma clara convicção de que todos morreriam em alguma etapa de suas vidas, que seriam advertidos sobre a sua morte e isso se daria através de sensações ou pela leitura dos sinais naturais como um pressentimento ou pelos eventos da natureza. O morrer seguia com um protocolo conhecido por todos: esperavam-se gestos, rituais e comportamentos adequados para isto. O ritual de morte era presidido pelo enfermo, geralmente na sua residência e acamado, cujo primeiro ato era o lamento da vida, uma evocação triste, mas discreta, dos seres e das coisas amadas. O segundo ato era o perdão dos companheiros que rodeavam o leito do moribundo. E o terceiro era o momento de esquecer o mundo e de pensar em Deus e aguardar a morte. Ariès (1977) nos traz esse dado histórico que contrapõe ao que vivemos na hipermodernidade, no Ocidente. No período da "morte domada" havia o consentimento generalizado pela espera da morte, não sem tristeza, mas com um conformismo porque se sabia que todos morreriam dando o tom de familiaridade com a morte. Na concepção hipermoderna, a idéia de morte é tida como um evento a ser evitado que causa profundo estranhamento e que deve ser controlado pela ciência, principalmente as biotecnologias, cujo poder está sendo alçado a de "superar a morte". Atualmente, o hospital, impassível, e não mais a residência do sujeito acometido por doença terminal, é quem faz a gestão do adoecimento e da morte e existe uma barreira cultural onde falar da morte e do luto é inadequado e indesejável.

\section{Considerações finais}

Pudemos perceber que o enfrentamento da morte passou e passará por diversos modos que estão atrelados ao meio cultural e social da época, desde a plena admissão de sua ocorrência, da proximidade e do distanciamento da morte, até a tentativa de diminuir a ansiedade diante da proximidade da morte por meio de drogas alucinógenas que estimulam a experiência mística e a aproximação do sagrado. Se antes a religião tinha um papel de mediar e dar significado à terminalidade humana, nos parece que a contemporaneidade oferece como alternativa as biotecnologias para lidarmos com a morte, seja por meio da decodificação da experiência mística, seja tratando da angústia existencial através da medicação.

\section{POLÊM!CA $\mid$ LABORE}


Admitir que somos "humanos, demasiadamente humanos" (SIBILIA, 2002) é aceitar que somos seres incompletos, imperfeitos e impotentes e que os remédios também têm suas limitações e muitas vezes podem servir como um anestésico para fugir da realidade. É uma época em que o erro e o fracasso são condenáveis ao obscurantismo, e do indivíduo espera-se o máximo de eficiência e que esteja sempre "mais que bem", o que gera expectativas de ganhos e sucesso incessantes, o sentimento de medo e fracasso rondam e assombram o homem hipermoderno.

Na hipermodernidade há um grande esforço de prover a satisfação do homem, seja pelo viés do consumo, seja pela promessa das biotecnologias em levá-lo ao auge da sua realização. A ciência e a tecnologia são interpretadas como instrumentos de previsibilidade e de controle de fenômenos que muitas vezes escapam do seu poderio como a morte ou a experiência mística. Tal cenário contemporâneo tem nos ensinado a nos distanciar da morte e do morrer através das descobertas científicas cada vez mais "promissoras" no sentido de eliminar a morte ou de pelo menos suavizar o peso que ela nos traz, no entanto, até que algum antídoto para a mortalidade seja inventado, a morte estará sempre presente, e por isso, devemos lidar com a sua presença inevitavelmente.

\section{Referências bibliográficas}

ARIÈS, Philippe. História da morte no ocidente. Rio de Janeiro: Francisco Alves, 1977.

BAUMAN, Zygmunt. Modernidade líquida. Rio de Janeiro: Zahar Ed., 2001.

BEZERRA Jr., Benilton. A psiquiatria e a gestão tecnológica do bem-estar. In: FREIRE FILHO, João (Org). Ser feliz hoje: reflexões sobre o imperativo da felicidade. Rio de Janeiro: Ed. FGV, 2010. p.117-134.

BIRMAN, Joel. Muitas felicidades?! O imperativo de ser feliz na contemporaneidade. In: FREIRE FILHO, João (Org). Ser feliz hoje: reflexões sobre o imperativo da felicidade. Rio de Janeiro: Ed. FGV, 2010. p. 27-47.

BLACK MIRROR. Otto Bathurst, Euros Lyn, Brian Welsh, Owen Harris, Bryn Higgins, Carl Tibetts. Inglaterra, 2011.

CHARLES, Sébastien. O individualismo paradoxal: introdução ao pensamento de Gilles Lipovetsky. In: LIPOVETSKY, Gilles. Os tempos hipermodernos. São Paulo: Ed. Barcarolla, 2004.

DOCE REMÉDIO. Revista Piauí, edição 105, junho de 2015. Disponível em:

〈http://revistapiaui.estadao.com.br/edicao-105/anais-da-medicina/doce-remedio >. Acesso em 08/07/2015.

HARAWAY, Donna; KUNZRU, Hari; TADEU, Tomaz. Antropologia do ciborgue: as vertigens do póshumano. Belo Horizonte: Autêntica Editora, 2009.

LIPOVETSKY, Gilles. Os tempos hipermodernos. São Paulo: Ed. Barcarolla, 2004.

A sociedade da decepção. Barueri, SP: Manole, 2007.

\section{POLÊM!CA $\mid$ LABORE}

Polêmica - Revista Eletrônica da Uerj - Rua São Francisco Xavier, 524, $1^{\circ}$ andar

bloco D, sl.1001 • Tels.: +55 21 2334-4088 / 4087 • http://www.e-publicacoes.uerj.br/index.php/polemica/index http://www.labore.uerj.br • laboreuerj@yahoo.com.br 
MENEZES, Rachel Aisengart. Tecnologia e "morte natural": o morrer na contemporaneidade. Physis: Rev. Saúde Coletiva, RJ, v. 13, n. 2, p. 129-147, 2003.

A medicalização da esperança: reflexões em torno da vida, saúde/doença e morte. Rev. Antropol. Amazôn. (online), v. 5, n. 2, p. 478-498, 2013.

QUEIROZ, Veronica Santana. Morte e subjetividade na hipermodernidade: a perspectiva do Budismo da Nova Tradição Kadampa. 2013. 231f. Dissertação (Mestrado em Psicologia Social) - Instituto de Psicologia, Universidade do Estado do Rio de Janeiro, Rio de Janeiro, 2013.

ROBOCOP: O policial do futuro (RoboCop). Direção: Paul Verhoeven. EUA: Orion Pictures Corporation, 1987. 1h e 42 min, longa-metragem, Dolby SR, colorido, legendado.

SIBILIA, Paula. O homem pós-orgânico: corpo, subjetividade e tecnologias digitais. Rio de Janeiro: Relume Dumará, 2002.

O sonho da reprogramação corporal: Biotecnologias, ciências da vida e produção de subjetividade na sociedade contemporânea. In: NEUTZLING, Inácio; RUIZ, Castor M.M. Bartolomé. O (des)governo biopolítico da vida humana. São Leopoldo-RS: Unisinos e Casa Leiria, 2011. p. 123-145.

SILVA, Juremir Machado da. A sociedade da (in)comunicação e da (in)diferença. In: LIPOVESTKY, Gilles. A sociedade da decepção. Barueri, SP: Manole, 2007.

Recebido em: 25/02/2016.

Aceito em: 22/07/2016.

\section{POLÊM!CA $\mid$ LABORE}

